IZA DP No. 5473

In-Work Benefits and Unemployment

Mirco Tonin

Ann-Sofie Kolm

February 2011 


\title{
In-Work Benefits and Unemployment
}

\author{
Mirco Tonin \\ University of Southampton \\ and IZA \\ Ann-Sofie Kolm \\ Stockholm University
}

\section{Discussion Paper No. 5473 \\ February 2011}

\author{
IZA \\ P.O. Box 7240 \\ 53072 Bonn \\ Germany \\ Phone: +49-228-3894-0 \\ Fax: +49-228-3894-180 \\ E-mail: iza@iza.org
}

\begin{abstract}
Any opinions expressed here are those of the author(s) and not those of IZA. Research published in this series may include views on policy, but the institute itself takes no institutional policy positions.

The Institute for the Study of Labor (IZA) in Bonn is a local and virtual international research center and a place of communication between science, politics and business. IZA is an independent nonprofit organization supported by Deutsche Post Foundation. The center is associated with the University of Bonn and offers a stimulating research environment through its international network, workshops and conferences, data service, project support, research visits and doctoral program. IZA engages in (i) original and internationally competitive research in all fields of labor economics, (ii) development of policy concepts, and (iii) dissemination of research results and concepts to the interested public.
\end{abstract}

IZA Discussion Papers often represent preliminary work and are circulated to encourage discussion. Citation of such a paper should account for its provisional character. A revised version may be available directly from the author. 
IZA Discussion Paper No. 5473

February 2011

ABSTRACT

\section{In-Work Benefits and Unemployment ${ }^{*}$}

In-work benefits are becoming an increasingly relevant labour market policy, gradually expanding in scope and geographical coverage. This paper investigates the equilibrium impact of in-work benefits and contrasts it with the traditional partial equilibrium analysis. We find under which conditions accounting for equilibrium wage adjustments amplifies the impact of in-work benefits on search intensity, participation, employment, and unemployment, compared to a framework in which wages are fixed. We also account for the financing of these benefits and determine the level of benefits necessary to achieve efficiency in a labour market characterized by search externalities.

JEL Classification: J21, J38, H24

Keywords: in-work benefits, search, labour force participation, wage adjustment

Corresponding author:

Mirco Tonin

School of Social Sciences

University of Southampton

Southampton SO17 1BJ

United Kingdom

E-mail:m.tonin@soton.ac.uk

\footnotetext{
* We want to thank Lars Calmfors, John Hassler, Bruce Meyer, and seminar participants at SOLE, New York, Southampton University, University of Padova.
} 


\section{Introduction}

In-work benefits are becoming an increasingly relevant labour market policy. A number of countries have recently introduced, or are about to introduce, some type of benefit or tax credit conditioned on work (e.g. Australia, Belgium, Canada, Finland, France, Germany, Hungary, Ireland, Japan, Korea, the Netherlands, New Zealand, Slovakia, and Sweden). Yet, other countries have progressively extended the scope of existing programmes, which were originally targeted at a very small section of the labour force. For instance, the Earned Income Tax Credit (EITC) in the US, which in 1975, the year of its introduction, involved around six million families, is now the largest cash transfer programme for low income families at the federal level. In 2003, about twenty million families received a total of $\$ 34$ billion in benefits from the EITC. ${ }^{1}$ Also the United Kingdom has a more than 25-year history of in-work benefits and has seen a gradual increase in their scope.

The expansion of this type of programmes makes it increasingly relevant to account for their equilibrium impact on the labour market. Moreover, since the aim of introducing in-work benefits is often to decrease unemployment and increase labour force participation, it is particularly important to take involuntary unemployment, search effort, and participation into consideration when studying the impact of in-work benefits on labour market performance.

The aim of this paper is to study the equilibrium impact of in-work benefits in a simple analytical framework displaying involuntary unemployment and endogenous labour force participation. Using a search model of the Pissarides type (Pissarides, 2000), we show that an in-work benefit reduces equilibrium unemployment, moderates wages and boosts participation and search effort. Total employment increases as a result. Moreover, in labour markets with an inefficiently high unemployment rate, the positive effects on employment and labour force participation in equilibrium exceeds that in partial equilibrium. This indicates that partial equilibrium studies that keep the wages fixed tend to underestimate the beneficial effect of in-work benefits. Moreover, it also indi-

\footnotetext{
${ }^{1}$ See Eissa and Hoynes (2005) and Committee on Ways and Means (2004).
} 
cates that countries that have run small scale experiments with in-work benefits, in which case the effect on the equilibrium wage is limited, can expect larger effects if the scheme is introduced more generally. We include a proportional tax on wages to account for the financing of the benefit. This is an important aspect for a policy applying to a non negligible part of the workforce. We show that an in-work benefit financed with a proportional income or payroll tax provides the government with an instrument to reduce inefficiencies induced by search externalities. We derive the socially optimal level of in-work benefits which fully eliminates these inefficiencies.

The analytical results are followed up with numerical simulations to quantify the effects of IWB on labour market performance and derive the magnitude of socially optimal in-work benefits. The simulations show that accounting for equilibrium wage adjustment is quantitatively important to assess the impact of in-work benefits on employment and unemployment and that the correction of labour market distortions may warrant a level of benefits that is relatively high, but not far off from observed levels.

Considering in-work benefits in an equilibrium setting reveals that their impact on job creation is an important factor behind employment growth. Previous research has, on the other hand, almost exclusively been concerned with the supply-side effects of in-work benefits. On the empirical side, the evaluation of programmes' expansions in the US and the UK have shown that benefits are quite successful in terms of increasing labour supply and that it is the participation decision rather than the hour decision that is mostly affected by the EITC (see for the US Eissa and Liebman,1996, Meyer and Rosenbaum, 2001; for UK see Brewer and Browne, 2006, and Blundell, 2006). On the theoretical side the standard neoclassical labour supply model serves as the basis for predicting the effects of the EITC on work hours (Meyer, 2002, Eissa and Hoynes, 2006) or on the extensive (participation) margin (Saez, 2002). Also more policy oriented work is characterized by a supply-side approach: in recent microsimulation studies looking at the impact of introducing in-work benefits in European countries (Immervoll et al., 2007, Bargain and Orsini, 2005), the crucial variable is the elasticity of labour supply with respect to the net-of-tax wage rate.

Considering that an important aim of an EITC type of policy is to increase 
employment, which is an equilibrium outcome involving both supply-side and demand-side factors, the limited number of studies that have accounted for the demand side of the market might be surprising. However, some recent empirical papers have raised the question of how the EITC is likely to affect wages, and have tried to estimate the incidence of the EITC on wages in different ways. Leigh (2004) uses variations in US state EITCs to examine the effect of the policy on pre-tax wages. The study by Rothstein (2007) uses the federal expansion of the EITC in the mid-1990s to estimate the effects on wages of the policy. Leigh (2004) finds that wages are significantly reduced by the state EITC and Rothstein (2007) finds that women at the lower end of the skill distribution face lower wages than they would have faced without the federal expansion of the EITC.

Some recent model analyses of in-work benefits incorporate unemployment. Boone and Bovenberg (2004) stress the importance of in-work benefits in order to alleviate distortions in terms of an inefficiently low search effort among the unemployed. Boone and Bovenberg (2006) look at the optimal interaction between in-work benefits and welfare benefits and find a U-shaped relationship in which in-work benefits are aimed at poverty alleviation in countries with low welfare benefits (such as the US), while countries with generous social assistance (such as many European ones) need in-work benefits in order to maintain workers in the labour force. Although these two studies account for unemployment in their models, unemployment is exogenously imposed. Thus, when investigating the impact of an in-work benefit, there will be no effect on wages and unemployment as they are fixed by assumption.

A study that accounts for adjustments in wages while allowing for unemployment to be endogenously determined is Lise et al (2005). They simulate the general equilibrium effects of the Self Sufficiency Project (SSP) in Canada, using a search framework to model the specific institutional details. Their simulation results imply that accounting for equilibrium effects reduces, or actually reverses, the impact of the policy. For instance, unemployment increases and employment decreases following the introduction of SSP and the cost-benefit analysis changes from a net gain from the programme to a net cost once the equilibrium impact is accounted for. This is however due to the complex inter- 
actions between different policy rules that characterize the Canadian system.

This rather limited previous literature on the impact of in-work benefit on labour market performance is related to the more extensive literature on taxation of labour within the context of imperfect labour markets. A number of studies have investigated the impact of payroll and income taxes on wage formation and unemployment in union bargaining models, efficiency wage models, and search and matching models. For example, Pissarides (1998) show that payroll taxation in all these types of models will most likely have no impact on unemployment as the tax is fully shifted over onto workers. Cardullo and Linden (2007), however, show that employment subsidies to firms employing low skilled workers can increase employment. Also, increased progressiveness in the income tax schedule has been shown to have a wage moderating, and thus an employment stimulating, effect in all these types of models (see Holmlund and Kolm, 1995, and Sørensen, 1999). In addition, socially optimal income tax schedules has been studied within the context of imperfectly competitive labour markets. The study by Boone and Bovenberg (2002) conducts a normative analysis of the role of the tax system in alleviating labour-market imperfections and raising revenues. They derive the optimal income tax schedule within a static search framework and find, as we do in section 5 for tax financed in-work benefits, that the proper choice of tax schedule can fully restore efficiency created by search externalities. In particular, they show that the optimal income tax schedule is progressive with a marginal tax rate being equal to the one derived in this paper.

The principal contribution of this paper is to shed light on the various channels through which an in-work benefit affects labour market outcomes in equilibrium, in a setting with involuntary unemployment. We underline the importance of job creation, a channel that has been generally overlooked in the literature on in-work benefits. In particular, we show under which conditions accounting for equilibrium wage adjustment boosts the positive impact of benefits on labour market outcomes. Our results are derived both when financing of benefits is not accounted for and when benefits are financed through proportional taxation. Moreover, we quantify the magnitude of these effects through numerical simulations. The rest of the paper is organized as follows: the results are 
derived in a simple and stylized model in sections 2 and 3 . In section 4 , we contrast the analysis done in an equilibrium model of the labour market to partial equilibrium analysis, where wages do not adjust. Section 5 considers the case when the in-work benefit is financed with payroll taxes or proportional income taxes. Numerical simulations are conducted in sections 6 , and the last section concludes.

\section{The Model}

The economy consists of a population that is fixed in size and, without loss of generality, normalized to unity. The size of the labour force is endogenous. An individual chooses to participate in the labour force if the return of participation exceeds the return of non-participation. Individuals are heterogeneous with respect to the value of leisure enjoyed when not participating. A worker who participates in the labour force is either employed or searching for a job.

The economy is characterized by trading frictions due to the costly and timeconsuming matching of workers and firms. The matching process of vacancies and unemployed job searchers is captured by a concave and constant-returnsto-scale matching function, $X=h(v, s u)$, where $v$ is the vacancy rate and $u$ is the unemployment rate. The rates are defined relative to the labour force. The search intensity by an average worker is denoted by $s$.

The transition rate of the unemployed individual $i$ into employment is given by $s_{i} X / s u=s_{i} \lambda(\theta)$, where $\theta=v / s u$ denotes labour market tightness. Firms fill vacancies at the rate $X / v=q(\theta)$. Higher labour market tightness $\theta$ increases workers' probability of finding a job, but reduces the probability of a firm finding

a worker, i.e., $\lambda^{\prime}(\theta)>0$ and $q^{\prime}(\theta)<0$, where $\eta(\theta)=-\frac{q^{\prime}}{q} \theta$ is the elasticity of the expected duration of a vacancy with respect to tightness.

\subsection{Workers and Firms}

Let $E, U$, and $N$ denote the expected present values of employment, unemployment, and non participation. The flow value functions for an individual worker 
can be written as:

$$
\begin{aligned}
& r E_{i}=w_{i}+I W B-\phi\left(E_{i}-U_{i}\right), \\
& r U_{i}=-\sigma\left(s_{i}\right)+s_{i} \lambda(\theta)\left(E-U_{i}\right), \\
& r N_{i}=l_{i},
\end{aligned}
$$

where $r$ is the exogenous discount rate, $w$ is the wage, and $\phi$ the exogenous separation rate. $\sigma(s)$ captures the search costs of the unemployed, where $\sigma_{s}(),. \sigma_{s s}()>$.0 . The term $I W B$ represents the in-work benefit which is received only when employed. $l$ is the per period real value of leisure if not participating in the labour force which is assumed to be distributed in the population according to the cumulative distribution function $F(l)$.

The unemployed worker chooses search effort, $s_{i}$, so as to maximize the discounted value of unemployment, $U_{i}$, taking search effort by other unemployed workers, $s$, as well as other market variables, as given. This yields:

$$
\sigma_{s_{i}}(.)=\lambda(\theta)\left(E-U_{i}\right) .
$$

Thus, the unemployed worker chooses search effort so as to equalize the marginal return of search with the marginal cost of search.

The economy consists of a large number of small firms that employ one worker only. Let $J$ and $V$ denote the expected present values of an occupied and a vacant job, respectively. The asset equations of a specific occupied job and a vacant job can be written as:

$$
\begin{aligned}
& r J_{i}=y-w_{i}-\phi\left(J_{i}-V\right), \\
& r V=-k+q(\theta)(J-V),
\end{aligned}
$$

where $y$ is worker productivity and the vacancy cost is denoted by $k$.

\subsection{Wages, search, participation, and employment}

Matching frictions create quasi-rents for any matched pair providing a scope for Nash bargaining. ${ }^{2}$ In symmetric equilibrium with free entry,i.e. with $V=0$,

\footnotetext{
2 The threat point for the worker is given by the value of unemployment. Note that the value of unemployment is at least as high as the value of non participation for workers in
} 
the solution satisfies $\beta J=(1-\beta)(E-U)$, where $\beta$ is the worker's bargaining power. This condition and the flow value functions in (1)-(6) yield the wage rule:

$$
w=\beta(y+k s \theta)-(1-\beta)[I W B+\sigma(s)] .
$$

The job creation curve expressing tightness as a function of search is derived from (5) and (6) and the wage rule in (7). Similarly, search effort in equilibrium, where $s_{i}=s$, is derived conditional on tightness from (4) using the Nash bargaining solution and (6). This yields:

$$
\begin{aligned}
\frac{k(r+\phi)}{q(\theta)} & =(1-\beta)[y+I W B+\sigma(s)]-\beta s k \theta, \\
\sigma_{s}(s) & =\frac{\beta k \theta}{1-\beta},
\end{aligned}
$$

which determine search effort and tightness in equilibrium. Clearly, the equilibrium wage follows recursively from (7).

A worker enters the labour force into the state of unemployment by choosing to conduct search. It will be worthwhile to enter if the return from entering exceeds the return from not entering. The value of leisure of the worker who is indifferent between entering and not entering the labour force, i.e., $\hat{l}$, is determined by $r U=r N(\hat{l})$. Workers with a value of leisure higher than $\hat{l}$, i.e., $l_{i}>\hat{l}$, will choose non-participation, whereas workers with a value of leisure lower than $\hat{l}$, i.e., $l_{i} \leq \hat{l}$, will choose participation. Combining the condition for the marginal worker with the flow equations and the Nash bargaining solution, the cumulative distribution function for leisure pins down the labour force participation rate, $L F$, conditional on tightness and search:

$$
L F=F\left(\frac{s \beta k \theta}{1-\beta}-\sigma(s)\right) .
$$

In equilibrium, the flow into unemployment equals the flow out of unemployment, i.e., $\phi(1-u) L F=s \lambda(\theta) u L F$. The equilibrium unemployment rate the labour force. Thus, employed workers do not consider the option of dropping out of the labour force as a threat when bargaining over wages. 
is then given by:

$$
u=\frac{\phi}{\phi+s \lambda(\theta)},
$$

which depends positively on the separation rate and negatively on tightness and search intensity. The total number of employed workers is then given by:

$$
\text { Employment }=(1-u) L F \text {. }
$$

\section{Effects of in-work benefits}

This section derives the effects of in-work benefits on wage formation, search effort, unemployment and employment in equilibrium while ignoring the effects working through the financing of the benefit. This enables us to pin down the mechanism through which the in-work benefits works in a clear and transparent way. Section 5 will deal with the generalization of these results when proportional income or payroll taxation is used to finance the in-work benefit. We summarize the results in the following proposition:

Proposition 1 An in-work benefit will reduce wages and increase tightness and search effort. Moreover, an in-work benefit will reduce the rate of unemployment and increase labour force participation and employment.

Proof. See appendix.

An in-work benefit which, by definition, is conditioned on work, makes it relatively more attractive to have a job, so it tends to reduce wage demands. As wage demands fall, it becomes more profitable to open vacancies in relation to the number of efficient job searchers in the unemployment pool, which induces tightness to increase. As the expected unemployment spells become shorter, the return to job search increases, which induces unemployed workers to devote more time to search. The equilibrium rate of unemployment falls both because unemployed workers search more intensively for a job and because there are more posted vacancies relative to the number of efficient job searchers. The shorter expected unemployment spells will also increase the return to participation. Consequently, total employment increases both because the equilibrium rate 
of unemployment falls and because more workers choose to participate in the labour market.

The role of job creation becomes even more pronounced if we account for unemployment benefits in the analysis. Including fixed or wage indexed unemployment benefits in the present model will not modify the results in the proposition. However, when benefits are indexed to the wage, an increase in the in-work benefits have a larger effect on wage demands. This follows as the wage moderation entails a reduction in unemployment benefits, which further reduces the wage demands. In fact, the take home pay when employed, $w+I W B$, may fall in this case. However, even if labour income falls with an increase in the in-work benefit, search effort and participation increase. This follows as the expected unemployment spell becomes shorter. This illustrates a case when the employment increase caused by an in-work benefit is solely driven by job creation.

\section{Fixed wages}

In this section we contrast the labour market effects in the previous section, when we allowed for wage adjustments, with the labour market outcomes that would follow in a partial equilibrium framework, i.e. with fixed wages. Our results show that the positive effects on employment and labour force participation in equilibrium exceeds that in partial equilibrium if the unemployment rate is inefficiently high.

To contrast the fixed and flexible wage cases is relevant for a number of reasons. First, our results indicate that partial equilibrium studies that keep the wage fixed tend to underestimate the beneficial effect of introducing inwork benefits. It is thus important to allow for wage adjustments when deriving conclusions about the expected employment effects of in-work benefits. Second, countries that have run small scale experiments with in-work benefits, in which case the effect on the equilibrium wage is limited, can expect larger effects if the scheme is introduced more broadly. It may thus be misleading to base policy recommendations about the desirability of extending such schemes solely on the empirical evaluation of employment effects for small scale experiments. Third, 
the analysis sheds some light on the interaction with another important labour market policy: the minimum wage. In particular, countries with no binding minimum wages can potentially expect higher positive effects on employment than countries with binding minimum wages.

It follows from our model that when wages are fixed, an in-work benefit will increases search and labour force participation as the take-home pay increases. As supply creates its own demand, also employment increases. When wages are allowed to adjust, we know that wages fall. This is, on the one hand, bad for employment as the lower wage reduces the incentives to participate and search for a job, but, on the other hand, it is good for employment as firms create more jobs. This job creation reduces the expected unemployment spells, and therefore increases the incentives to participate and search. This exercise enables us to pin down a condition for when the latter effect dominates the former, implying that the positive effect on employment is larger when wages are allowed to adjust.

Contrasting the labour market outcomes in the two cases, we can conclude:

Proposition 2 An in-work benefit will have a larger positive impact on search effort and labour force participation in equilibrium, when wage adjustments are accounted for, than in partial equilibrium, when wages are assumed to be fixed, if and only if $\beta>\eta(\theta)$. The condition $\beta \geq \eta(\theta)$ is a sufficient condition for an in-work benefit to have a larger impact on employment and unemployment when wages adjust compared to when fixed.

Proof. See appendix.

Because of trading externalities, equilibrium search intensity and participation are too low from the point of view of society when $\beta>\eta(\theta)$. Wages are simply set too high and tightness too low from a social point of view (Hosios, 1990, and Pissarides, 2000). Under these circumstances, the positive effect on search effort due to the fact that job offers arrive more frequently will dominate the negative effect on search effort due to the fact that lower wages reduce the payoff from work. This holds also for the participation decision which is concerned with weighting the effects on the take-home pay against a higher job offer arrival rate for the unemployed. As the flexible wage case always brings 
wage moderation and a higher transition rate into employment, $\beta \geq \eta(\theta)$ is a sufficient condition for employment to increase and unemployment to fall with in-work benefits.

\section{$5 \quad$ Financing of the in-work benefit}

In this section, we study the effects of in-work benefits when their financing through proportional income taxation is taken into account. ${ }^{3}$ As only employed workers receive the benefits, the balanced budget condition is:

$$
I W B=t w .
$$

The flow value function for employment in (1) is now written:

$$
r E_{i}=w_{i}(1-t)+I W B-\phi\left(E_{i}-U_{i}\right),
$$

while (2), (3), (5), and (6) remain unchanged. To derive the equilibrium equations determining tightness, search and the wage we follow the same procedure as in the basic setting although now accounting for that $I W B=t w$ according to the balanced budget in (13). This yields the following equations:

$$
\begin{aligned}
w & =\frac{\beta(1-t)}{1-\beta t}(y+k s \theta)-\frac{1-\beta}{1-\beta t} \sigma(s), \\
\frac{k(r+\phi)}{q(\theta)} & =\frac{1-\beta}{1-\beta t}[y+\sigma(s)]-\frac{\beta(1-t)}{1-\beta t} k s \theta, \\
\sigma_{s}(s) & =(1-t) \frac{\beta k \theta}{1-\beta},
\end{aligned}
$$

which correspond to equations (7), (8) and (9) in the basic setting. From these equilibrium equations, it is straightforward to show that an increase in the proportional tax rate used to finance in-work benefits reduces wages and increases tightness, i.e., $\frac{\partial w}{\partial t}<0, \frac{\partial \theta}{\partial t}>0$. This translates into:

$$
\frac{\partial w}{\partial I W B}<0, \frac{\partial \theta}{\partial I W B}>0
$$

as long as the economy is on the side of the "Laffer curve" where an increase in the tax rate increases total revenues. The government budget constraint in (13)

\footnotetext{
${ }^{3}$ The $I W B$ being financed by payroll taxation would yield the same results.
} 
show that the relationship between the tax rate and the in-work, however, may not be monotonic. There is a direct positive effect of an increased tax rate, $t$, on government revenues, but there is also a negative effect on revenues as the tax base is eroded through wage moderation.

From (17) it is clear that search intensity grows with the tax rate only if the following condition holds:

$$
(1-t) \frac{\partial \theta}{\partial t}-\theta>0
$$

This is true also for labour force participation as $L F=F\left((1-t) \frac{s \beta k \theta}{1-\beta}-\sigma(s)\right)$. From the basic setting, in-work benefits unambiguously improved search and labour force participation as the shorter expected unemployment spells made it more attractive to look for a job. However, when the $I W B$ is financed with taxation, there is a counteracting effect because taxation directly reduces the payoff from work. This counteracting effect is captured by the second term on the left hand side in (18), while the first term captures improved incentives to search and participate due to that it has become easier to get a job. A rewriting of the condition in (18) gives:

$$
\frac{1-t}{1-\beta t} \beta>\eta(\theta)
$$

As will be shown below, the condition in (19) holds when tightness is below its socially efficient level. The condition in (19) is, however, only a sufficient, not a necessary, condition for unemployment to fall and employment to increase with tax financed in-work benefits. ${ }^{4}$ We can conclude the following:

Proposition 3 Proposition 1 holds also when in-work benefits are financed through proportional taxes on wages, provided a higher tax rate implies higher fiscal revenues and that $\frac{1-t}{1-\beta t} \beta>\eta(\theta)$.

Proof. See appendix.

It is straightforward to show that tightness is at its socially efficient level when $\frac{1-t}{1-\beta t} \beta=\eta(\theta)$. This condition should be compared to the standard Hosios

\footnotetext{
${ }^{4}$ Unemployment and employment is still given by (11) and (12), respectively. Unemployment will certainly fall with $t$ if search intensity increases with $t$. Employment increases with certainty when $t$ increases if labour force participation increases and unemployment falls.
} 
condition, $\beta=\eta(\theta)$, which is needed in order to reach social efficiency when there is no tax financed in-work benefit available in the economy (Hosios, 1990, Pissarides, 2000). To do this notice that equilibrium tightness and search when in-work benefits are financed through proportional taxation are given by equations (16) and (17), while the wage is given by equation (15). Exactly the same expressions are derived when substituting $\beta$ with

$$
\beta^{\prime} \equiv \frac{1-t}{1-\beta t} \beta<\beta
$$

and $I W B=0$ into the equations (8), (9), and (7) which then characterize the equilibrium with no $I W B$. This means that the equilibrium of a model with inwork benefits financed through a proportional tax on wages $t$ and with workers' bargaining power $\beta$ is isomorphic to the equilibrium of a model without in-work benefits and with workers' bargaining power $\beta^{\prime}<\beta$. Thus, an increase in the tax rate used to finance in-work benefits is equivalent to reducing the "effective" bargaining power of the worker. This suggests that tax financed in-work benefits provides the government with an instrument to reduce the worker's "effective" bargaining power, and thereby enables policy makers to improve efficiency in the economy when $\beta>\eta(\theta)$. Under these circumstances a marginal increase in taxation moves the labour market toward efficiency, thus increasing search intensity and participation and reducing unemployment. We can conclude the following:

Proposition 4 The government can use tax financed in-work benefits to reduce worker's effective bargaining power and thereby improve efficiency. The tax rate, or the IWB as a proportion of the wage, inducing efficiency is $t=I W B / w=$ $\frac{\beta-\eta(\theta)}{\beta(1-\eta(\theta))}$.

Proof. See appendix.

For the case of a Cobb-Douglas matching function, the socially efficient tax rate is given by $t=\frac{\beta-\eta}{\beta(1-\eta)}$, as $\eta$ then is constant. The $I W B$ inducing constrained efficiency is $I W B=\frac{\beta-\eta(\theta)}{\beta(1-\eta(\theta))} w(\theta)$, where the wage is the equilibrium wage outcome from (15) when tightness is at its socially efficient level.

Next we turn to some numerical simulations in order to determine under which conditions expression (19) holds and to provide examples of the magnitude 
of the effects of IWB on labour market performance.

\section{Numerical simulations}

First we determine for which range of marginal tax rates the efficiency condition in (19) holds, given the value of $\beta$ and $\eta$. As $\beta \in[0,1]$, for $t$ to belong to the interval $[0,1]$, we need that $\beta>\eta(\theta)$. The values for $\eta$ used in the literature vary widely. For instance, Hall (2005) uses 0.24, while Shimer (2005) uses 0.72.5 Petrongolo and Pissarides (2001) in their literature survey consider $[0.5,0.7]$ to be the range of plausible values. There are not many estimates of $\beta$. The conventional value of $\beta$ used in the literature is 0.5, although Flinn (2006) provides a point estimate of 0.4 .

Given the uncertainty surrounding the value of these parameters, we calculated the highest tax rate under which expression (19) is satisfied for the whole range of admissible values of $\beta$ and $\eta$ (see Figure 1). As far as the workers' bargaining power is higher than the level achieving social efficiency, and thus it makes sense to use in-work benefits from a social planner perspective, the condition under which the labour market improves when financing is taken into account is satisfied for a wide range of marginal tax rates. For example, when $\beta=0.6$ and $\eta=0.4$, an increase in fully-financed benefits moves the economy towards efficiency as far as $t<0.56$. When $\beta=0.4$ and $\eta=0.3$, this is the case for $t<0.36$. Thus, there is room for in-work benefits to play an important role in improving labour market outcomes.

Another way to assess the potential role of benefits is to quantify what their optimal level is. At the end of the previous section, it has been shown how to derive the $I W B$ inducing constrained efficiency. For the purpose of comparing the optimal level to observed levels in existing programmes, it is more useful to look at the level of benefits as a percentage of the wage. Given (13), this is equivalent to $t$ and thus can be read in Figure 1 for each value of $\beta$ and $\eta$, as the highest tax rate under which expression (19) is satisfied is the one inducing efficiency. Thus, for $\beta=0.4$ and $\eta=0.3$, the optimal in-work benefit would be $36 \%$ of the wage. By comparison, the credit rate in the phase-in area of the

\footnotetext{
${ }^{5}$ See Gertler and Trigari (2009) for a review of values used in other studies.
} 
EITC, and thus the ratio between the in-work benefit and the wage for incomes within the phase-in area, is $7.65 \%$ in case of no children, $34 \%$ with one child, and $40 \%$ and $45 \%$ respectively with two and three children.

Given the simplicity of the model and the uncertainty surrounding the value of the main parameters, these calculations are only indicative. Nonetheless, they suggest that benefits of a substantial size, but not far off from observed levels, may be needed to correct labour market inefficiencies due to search externalities.

In the rest of this section we calibrate the model to gauge insights about the quantitative impact of in-work benefits on the main labour market variables. First, we compare the impact of benefits with and without wage adjustment when financing is not accounted for. Then, we look at the model with financing.

\subsection{Calibration}

To calibrate the model, we assume a Cobb-Douglas matching function:

$$
X=h(v, s u)=m v^{1-\eta}(s u)^{\eta} \quad \text { where } m>0 ; \eta \in(0,1) .
$$

The convex search cost function is assumed to be a power function and therefore

$$
\sigma(s)=s^{\alpha}, \text { where } \alpha>1 \text {. }
$$

The month is the basic time unit. Productivity $y$ is normalized to 1 . Worker bargaining power $\beta$ is set to the standard value in the literature of 0.5 , while the real interest rate $r$ is 0.005 . Following Christensen et al. (2005), parameter $\alpha$ equals 2 , implying a quadratic search cost. $^{6} \eta$ equals 0.4 , while parameters $k, \phi$, and $m$ are set to replicate an unemployment rate of 0.06 , an average duration of unemployment of three months, and an average duration of a vacancy of one month in the absence of in-work benefits, giving $k=4.5616, \phi=0.0213$, and $m=0.6807$. Finally, we assume the per period value of leisure to be distributed according to an exponential function with parameter $\mu$, calibrated

\footnotetext{
${ }^{6}$ Christensen et al. (2005) structurally estimate a model with on-the-job search using Danish microdata. A quadratic function is also the preferred specification in Yashiv (2000), who structurally estimates a model with search only by the unemployed using Israeli aggregate time-series data.
} 
so that the participation rate without in-work benefits equals 0.7 . The table below summarizes the parametrization.

\begin{tabular}{|ccccccccc|}
\hline$y$ & $\beta$ & $k$ & $r$ & $\phi$ & $m$ & $\eta$ & $\alpha$ & $\mu$ \\
\hline 1 & 0.5 & 4.5616 & 0.005 & 0.0213 & 0.6807 & 0.4 & 2 & 0.631 \\
\hline
\end{tabular}

\subsection{Numerical results with flexible and fixed wages}

The theory predicts stronger effects on labour market performance of in-work benefits when wages adjust in comparison to when wages are fixed, in the case when unemployment is inefficiently high. This section investigates the magnitude of these differences.

The simulation results show that the quantitative impact on unemployment and employment is significantly stronger when the effect of benefits on wages is taken into account. Figure 2 describes the effects on the main labour market variables of introducing in-work benefits up to the equivalent of half of labour productivity. The continuous line represents the case where wages are flexible, while the dotted line represents the case with fixed wages. Compared to an unemployment rate of $6 \%$ without in-work benefits, the introduction of benefits equivalent to $40 \%$ of productivity implies a decline in unemployment to $4.97 \%$ when wages are fixed and to $4.41 \%$ when they are flexible, while employment increases by an additional $0.62 \%$ with flexible wages as compared to the case with fixed ones (see Table 1).

These results suggest that the extension of benefits to larger portions of the workforce does not entail, in itself, a decline in their effectiveness or, worse, a reversal of their effect. In the next section we look at another issue that needs to be taken into account when the scope of benefit programmes is increased to comprise a non negligible share of the workforce: their financing.

\subsection{Numerical results with financing}

Here we use the same parametrization as in the previous section to compare the effects on labour market performance of fully-financed benefits up to the 
equivalent of half of labour productivity. ${ }^{7}$ Adjustable wages and fixed wages are considered in turn.

In Figure 3, the continuous line represents the flexible wage case, while the dotted line represents the case with fixed wages. When benefits are fully financed by taxing beneficiaries and wages are downward rigid, in-work benefits do not have any effect. When wages can adjust, tightness increases and gross wage decreases. Notice that in this setting, gross wage is equivalent to total income, as fiscal revenues are entirely used to finance benefits. The comparison of figures 2 and 3 reveals that both tightness and wages respond more strongly when benefits are financed through taxation on beneficiaries' wages as compared to the case when an identical amount of in-work benefits is financed through other sources. This is due to the additional wage moderation stemming from taxation. On the other hand, for a given amount of benefits, search intensity, labour force participation, and employment responds much less with proportional taxes on wages than without. For unemployment the response in the two cases is similar. As predicted by the theory, with full financing the response of search intensity and labour force participation is hump-shaped, initially increasing with the level of benefits (and taxes) and then declining. The tax rate at which both quantities reach their peak is $t=1 / 3$, corresponding to $I W B \approx 0.28$, at which (constrained) efficiency is achieved. Further increases in fully financed benefits take the labour market away from efficiency. However, search intensity and participation stay above the level they have when no benefits are paid until $I W B \approx 0.47(t \approx 56 \%)$. Unemployment declines in the whole range, falling, for instance, from $6 \%$ to $4.15 \%$ when benefits are equivalent to $40 \%$ of productivity. Total employment increases, reaching approximately $67.2 \%$ of the population when $I W B=0.4$, as compared to $65.8 \%$ with no benefits (see Table 1).

\footnotetext{
${ }^{7}$ The tax rate corresponding to $I W B=0.5$ is approximately $60 \%$. Given this parametrization, the maximum attainable amount of benefits with wage flexibility is 0.64 , achieved at a tax rate of $88 \%$.
} 


\section{Conclusions}

In-work benefits are becoming increasingly popular among policy-makers due to their success in the American and British contexts. Whether this success can be extended to larger sections of the workforce and to other countries is an open issue. This paper represents a first step towards addressing this question.

We analyze the impact of in-work benefits on some of the main labour market indicators in a search framework, taking into account the effects on labour market equilibrium. We find that in-work benefits increase labour force participation, employment, and search intensity by the unemployed, while wages and the unemployment rate decline.

Moreover, we show that the positive effect on employment and labour force participation in equilibrium exceeds that in partial equilibrium, i.e., when wage are fixed, if the unemployment rate is inefficiently high. Results from numerical simulations suggest that the quantitative impact on unemployment and employment is significantly larger when the effect of benefits on wages is taken into account.

The results derived from contrasting the fixed and flexible wage cases have important policy implications. If in-work benefits are introduced as small scale experiments, in which case the effect on the equilibrium wage is indeed limited, then the evaluation of their impact on labour market outcomes will tend to underestimate the beneficial effect of introducing in-work benefits more broadly. Indeed, countries that have run small scale experiments with in-work benefits can expect larger effects if the scheme is extended. Also, the analysis sheds some light on the interaction of in-work benefits and a minimum wage. Countries with no binding minimum wages can potentially expect higher positive effects on employment than countries with binding minimum wages.

Finally we did derive the socially optimal amount of in-work benefits. It turns out that the government can use tax financed in-work benefits to reduce worker's effective bargaining power and thereby reduce inefficiencies induced by search externalities. Numerical simulations suggest that benefits of a substantial size, although not far off from observed levels, may be needed in order to correct labour market inefficiencies due to search externalities. 


\section{References}

[1] Blundell, R., 2006. Earned income tax policies: impact and optimality. Journal of Labour Economics 13, 423-443.

[2] Brewer, M., and Browne, J., 2006. The effect of the working families' tax credit on labour market participation. BN No 69, the Institute for Fiscal Studies.

[3] Boone J., and Bovenberg, L., 2002. Optimal labour taxation and search. Journal of Public Economics 85, 53-97.

[4] Boone J., and Bovenberg, L., 2004. The optimal taxation of unskilled labour with job search and social assistance. Journal of Public Economics 88, 22272258 .

[5] Boone J., and Bovenberg, L., 2006. Optimal welfare and in-work benefits with search unemployment and observable abilities. Journal of Economic Theory 126, 165-193.

[6] Committee on Ways and Means, 2004. 2004 Green Book. U.S. House of Representatives.

[7] Cardullo G., and Van der Linden B., 2007. Employment subsidies and substitutable skills: An equilibrium matching approach. Applied Economics Quarterly 53, 375-404.

[8] Christensen, B. J., Lentz, R., Mortensen, D. T., Neumann, G. R., and Wervatz, A., 2005. On the job search and the wage distribution. Journal of Labor Economics 23, 31-58.

[9] Eissa, N., and Hoynes, H., 2006. Behavioral responses to taxes; Lessons from the EITC and labour supply. Tax Policy and the Economy 20, 73110.

[10] Eissa, N., and Liebman, J., 1996. Labor supply responses to the earned income tax credit. Quarterly Journal of Economics 111, 605-637. 
[11] Flinn, C. 2006. Minimum Wage Effects on Labor Market Outcomes under Search, Bargaining and Endogenous Contact Rates. Econometrica 74, 1013-62.

[12] Gertler, M., and Trigari, A., 2009. Unemployment Fluctuations with Staggered Nash Wage Bargaining. Journal of Political Economy 117(1), 38-86.

[13] Hall, R., 2005. Employment Fluctuations with Equilibrium Wage Stickiness. American Economic Review 95 (1), 50-65.

[14] Holmlund, B., and Kolm, A-S., 1995, Progressive taxation, wage setting, and unemployment: Theory and Swedish evidence, Swedish Economic Policy Review 2, 423-460.

[15] Hosios, A, 1990. On the efficiency of matching and related models of search and unemployment. Review of Economic Studies 57(2), 279-298.

[16] Immervoll, H., Kleven, H., Kreiner, C.T. and Saez, E., 2007. Welfare reform in European countries: A micro simulation analysis. Economic Journal 117, $1-44$.

[17] Leigh, A., 2004. Who Benefits from the Earned Income Tax Credit? Incidence Among Recipients, Coworkers and Firms, ANU CEPR Discussion Paper 494.

[18] Lise, J., Shannon, S., and Smith, J., 2005. Equilibrium policy experiments and the evaluation of social programs. IZA Working Paper 758.

[19] Meyer, B., and Rosenbaum, D., 2001. Welfare, the earned income tax credit and the labour supply of single mothers. Quarterly Journal of Economics $116,1063-1114$.

[20] Meyer B., 2002. Labor Supply at the Extensive and Intensive Margin, the EITC, Welfare and Hours Worked. American Economic Review. Papers and Proceedings 92, 373-379.

[21] Michalopoulos C., Robins, P.K., and Card, D., 2005. When Financial Work Incentives Pay for Themselves; Evidence from a Randomized Social Experiment for Welfare Recipients. Journal of Public Economics 89, 5-29. 
[22] Petrongolo, B., and Pissarides, C. 2001. Looking into the Black Box: A Survey of the Matching Function. Journal of Economic Literature 39(2), 390-431.

[23] Pissarides, C., 1998. The impact of employment tax cuts on unemployment and wages: The role of unemployment benefits and the tax structure. European Economic Review 42, 155-183.

[24] Pissarides, C., 2000. Equilibrium unemployment theory, MIT Press, Boston, MA.

[25] Rothstein, J., 2004. The Unintended Consequences of Encouraging Work: Is the EITC As Good As an NIT?, mimeo.

[26] Saez, E., 2002. Optimal Income Transfer Programs: Intensive Versus Extensive Labor Supply Responses. Quarterly Journal of Economics 117, 1039-1073.

[27] Shimer, R., 2005. The Cyclical Behavior of Equilibrium Unemployment and Vacancies. American Economic Review 95 (1), 25-49.

[28] Sørensen, P.B., 1999. Optimal tax progressivity in imperfect labor markets. Labour Economics 6, 435-452.

[29] Yashiv, E., 2000. The determinants of equilibrium unemployment. The American Economic Review 90, 1297-1322.

\subsection{Appendix: Proofs of Propositions}

Proposition 1. Differentiation of (8) with respect to $\theta$ and $I W B$ yields

$\frac{\partial \theta}{\partial I W B}=\frac{(1-\beta)}{s \beta k\left(1-k(r+\phi) \frac{q^{\prime}}{s \beta k q^{2}}\right)}>0$. To get the equilibrium effect on tightness, we need to account for the fact that $s$ is a function of $\theta$ through (9). However, as search is optimally determined by workers, the effects working through search effort in (8) will have no impact on tightness. Using how $I W B$ affects tightness and the fact that search is optimally determined, we can show the following 
for search effort, wage, income from work, labour force participation, the unemployment rate, and employment: $\frac{\partial s}{\partial I W B}=\frac{\beta k}{\sigma_{s s}(s)(1-\beta)} \frac{\partial \theta}{\partial I W B}>0$ from (9), $\frac{\partial w}{\partial I W B}=-(1-\beta)\left[1-1 /\left(1-k(r+\phi) \frac{q^{\prime}}{s \beta k q^{2}}\right)\right]<0$ from $(7), \frac{\partial(w+I W B)}{\partial I W B}=$ $-(1-\beta)\left[1-1 /\left(1-k(r+\phi) \frac{q^{\prime}}{s \beta k q^{2}}\right)\right]+1>0, \frac{\partial L F}{\partial I W B}=F^{\prime}(.) \frac{s \beta k}{(1-\beta)} \frac{\partial \theta}{\partial I W B} \geq 0$ from (10), $\frac{\partial u}{\partial I W B}=-\frac{\phi}{\phi+s(\theta) \lambda(\theta)}\left(\frac{\partial s}{\partial \theta} \lambda(\theta)+s \frac{\partial \lambda}{\partial \theta}\right) \frac{\partial \theta}{\partial I W B}<0$ from (11), and $\frac{\partial E m p l o y m e n t}{\partial I W B}=-\frac{\partial u}{\partial I W B} L F+(1-u) \frac{\partial L F}{\partial I W B}>0$ from (12).

Proposition 2. With wages fixed at the pre-benefit level $\tilde{w}$, tightness is derived from (5) and (6) and given by: $k(r+\phi) / q(\theta)=y-\tilde{w}$. Combining (1) and (2), we obtain $E-U=(\tilde{w}+I W B+\sigma(s)) /(r+\phi+s \lambda(\theta))$, which used in (4) gives search effort given by: $\sigma_{s}()=.\lambda(\theta)(\tilde{w}+I W B+\sigma(s)) /(r+\phi+s \lambda(\theta))$. Total differentiation of this expression for search yields: $\frac{\partial s}{\partial I W B}=\frac{\lambda(\theta)}{N}+\frac{A}{N}$ where $N=\sigma_{s s}(s)(r+\phi+s \lambda(\theta))$ and $A=\lambda(\theta) \frac{\partial w}{\partial I W B}+\frac{\partial \lambda(\theta)}{\partial \theta} \frac{1}{\lambda(\theta)} \frac{\partial \theta}{\partial I W B} \sigma_{s}().(r+\phi)$. The first term captures the direct effect (and only effect if wages are fixed) and the second term captures the effects due to flexible wages. As the first term is the same in the fixed and flexible case, the effect on search due to wage adjustments depends on the sign of the second term. Using the expressions in the proof of proposition 1 and the fact that $\lambda(\theta)=q \theta$ and $\frac{\partial \lambda(\theta)}{\partial \theta}=$ $q^{\prime} \theta+q$, we have $A=\frac{(r+\phi)}{(s \beta+(r+\phi) \eta(\theta) / \lambda(\theta))}[\beta-\eta]>0 \leftrightarrow \beta>\eta$. Labour force is given by $L F=F\left(s \lambda(\theta) \frac{\tilde{w}+I W B+\sigma(s)}{r+\phi+s \lambda(\theta)}-\sigma(s)\right)$, which can be rewritten using the expression for search as: $L F=F\left(s \sigma_{s}(s)-\sigma(s)\right)$. Differentiation yields $\frac{\partial L F}{\partial I W B}=F^{\prime}(). s \sigma_{s s}(s) \frac{\partial s}{\partial I W B}$. Therefore, the condition for labour force participation to increase more with a marginal increase in $I W B$ under flexible wages is the same as the one for search intensity. The expressions for unemployment and employment are unchanged given by (11) and (12). Differentiation yields $\frac{\partial u}{\partial I W B}=-\frac{\phi}{\phi+s(\theta) \lambda(\theta)}\left(\frac{\partial s}{\partial I W B} \lambda(\theta)+s \frac{\partial \lambda(\theta)}{\partial \theta} \frac{\partial \theta}{\partial I W B}\right)$. Thus the unemployment rate tends to fall by more when wages are flexible as the higher tightness increases the transition rate into employment irrespective of whether $\beta$ is larger or smaller than $\eta$. However, if $\beta>\eta(\theta)$, search increases by more if wages are flexible, and thus we have an additional negative effect on the unemployment rate, making $\beta>\eta(\theta)$ a sufficient but not necessary condition for unemployment to decline more when wages are flexible. This is also the case for employment, as $\frac{\partial E m p l o y m e n t}{\partial I W B}=-\frac{\partial u}{\partial I W B}+(1-u) \frac{\partial L F}{\partial I W B}$. 
Proposition 3. Differentiating (16) with respect to $t$ and $\theta$ yields $\frac{d \theta}{d t}=$ $\frac{(1-\beta)[y+k s \theta+\sigma(s)]}{(1-\beta t) s k(1-t)[1+z]}>0$, where $z=-\frac{(r+\phi) q^{\prime}}{q^{2}} \frac{(1-\beta t)}{(1-t) s \beta}>0$. Note that changes in $t$ working through $s$ can be ignored as $s$ is optimally chosen by the individuals. Differentiating (17) wrt $t$ and $s$ yields

$\frac{d s}{d t}=\frac{\beta k}{\sigma_{s s}(1-\beta)}\left((1-t) \frac{d \theta}{d t}-\theta\right)$. Differentiating $L F=F\left((1-t) \frac{s \beta k \theta}{1-\beta}-\sigma(s)\right)$ wrt $L F$ and $t$ yields $\frac{d L F}{d t}=F^{\prime}(.) \frac{\beta k}{\sigma_{s s}(1-\beta)}\left((1-t) \frac{d \theta}{d t}-\theta\right)$, where we again note that changes in $t$ working through $s$ can be ignored as $s$ is optimally chosen by the individuals. Substitute the expression of $\frac{d \theta}{d t}$ derived in this proof into (18) and use (16) one gets that search and $L F$ increases with $t$ if $\frac{1-t}{1-\beta t} \beta>\eta(\theta)$. Differentiating (11) yields that unemployment tends to fall with $t$ as tightness always increases with $t$. As more search also reduces unemployment, the effect on unemployment of higher taxes is reinforced if $\frac{1-t}{1-\beta t} \beta>\eta(\theta)$, and dampened, or possibly more than counteracted, when $\frac{1-t}{1-\beta t} \beta<\eta(\theta)$. Differentiating (12) yields that employment increases with $t$ if $u$ falls with $t$ and or $L F$ increases with $t$. Thus $\frac{1-t}{1-\beta t} \beta>\eta(\theta)$ is a sufficient, but not necessary condition for $u$ to fall and employment to increase with $t$. The results of the first proposition thus holds if $\frac{1-t}{1-\beta t} \beta>\eta(\theta)$, and if it is the case that a higher $I W B$ is financed with a higher tax rate rather than a lower tax rate. Using (15) in (13) and differentiating wrt $t$ and $I W B$ we get $\frac{d I W B}{d t}=\frac{\left(\beta t^{2}-2 t+1\right) \beta[y+k s \theta+\sigma(s)]}{(1-\beta t)^{2}}+\frac{\beta k s t(1-t)}{1-\beta t} \frac{d \theta}{d t}-\sigma(s)$. The first term is positive iff $t \in\left[0, \frac{1-\sqrt[2]{1-\beta}}{\beta}\right] \supset\left[0, \frac{1}{2}\right]$. The second term is always positive as $\frac{d \theta}{d t}>0$. So, for $\sigma(s)$ small enough and $t$ not too high $\frac{d I W B}{d t}>0$. Substituting the expression for $\frac{d \theta}{d t}$ we get $\frac{d I W B}{d t}=\frac{\beta[y+k s \theta+\sigma(s)]}{1-\beta t}\left[(1-t)-\frac{t(1-\beta)}{(1-\beta t)}\left(1-\frac{1}{1+z}\right)\right]-\sigma(s)$. Notice that at $t=0, \frac{\partial I W B}{\partial t}=w>0$.

Proposition 4. The social welfare function is $S W=(1-u) L F r E+$ $u L F r U+\int_{\hat{l}}^{l \max } l d l+(1-u) L F r J+v r V$. Rewritten using the flow value functions in equilibrium $((14),(2),(5),(6))$ as well as the flow equilibrium condition, i.e., $\phi(1-u) L F=q(\theta) v=s \lambda(\theta) u L F$, and the budget constraint in (13) we have $S W=-L F u \sigma(s)+\int_{\hat{l}}^{l \max } l_{i} d l_{i}+(1-u) L F y-s \theta u L F k$ when $r$ approaches zero. The tax rate will influence social welfare through its impact on tightness, unemployment, search, labour force, and leisure consumption of the marginal worker. The total derivative of $S W$ wrt $t$ is given by: 


$$
\begin{aligned}
\frac{d S W}{d t}= & {[-u \sigma(s)+(1-u) y-s \theta u k] \frac{d L F}{d t} } \\
& +\left[-L F u \sigma_{s}(s)-\theta u L F k-[L F \sigma(s)+L F y+s \theta L F k] \frac{d u}{d s}\right] \frac{d s}{d t} \\
& -\hat{l} \frac{d \hat{l}}{d t}-\left[(L F \sigma(s)+L F y+s \theta L F k) \frac{\partial u}{\partial \theta}+s u L F k\right] \frac{d \theta}{d t}
\end{aligned}
$$

where $\frac{d L F}{d t}=\frac{d s}{d t}=\frac{d \hat{l}}{d t}=0$ if $t=\frac{\beta-\eta}{\beta(1-\eta)}$ (see the proof of the previous proposition). Thus if $t=\frac{\beta-\eta}{\beta(1-\eta)}$ only the last term on the right hand side of $\frac{d S W}{d t}$ remains, where we know that $\frac{d \theta}{d t}>0$. A closer examination reveals that the last bracket on the right hand side is zero only when $\eta(\theta)=\frac{1-t}{1-\beta t} \beta$ which holds only when $t=\frac{\beta-\eta}{\beta(1-\eta)}$. This last bracket on the right hand side captures namely the effects derived in Pissarides (2000) working through the direct effect of tightness on vacancy costs and the impact of tightness working through unemployment given search effort, i.e., $\frac{\partial u}{\partial \theta}$. By allowing for tax financed in-work benefits, the government now has an instrument to reach constrained efficiency when $\beta>\eta(\theta)$. 


\subsection{Appendix 2: Figures and Tables}

Table 1: Main labour market variables

\begin{tabular}{|c|c|c|c|c|c|c|c|c|}
\hline \multirow[b]{2}{*}{$\mathbf{I W B}=0$} & & \multirow[t]{2}{*}{$t$} & \multirow{2}{*}{$\begin{array}{c}\theta \\
0.382\end{array}$} & \multirow{2}{*}{$\begin{array}{c}s \\
0.872\end{array}$} & \multirow{2}{*}{$\begin{array}{c}w \\
0.880\end{array}$} & \multirow{2}{*}{$\frac{L F}{70.0 \%}$} & \multirow{2}{*}{$\begin{array}{c}u \\
6.00 \%\end{array}$} & \multirow{2}{*}{$\begin{array}{c}e \\
65.8 \%\end{array}$} \\
\hline & & & & & & & & \\
\hline \multicolumn{9}{|l|}{$\mathrm{IWB}=0.2$} \\
\hline \multirow[t]{2}{*}{ No financing } & Fixed wage & & 0.382 & 0.973 & 0.880 & $77.7 \%$ & $5.41 \%$ & $73.5 \%$ \\
\hline & Flexible wage & & 0.427 & 0.974 & 0.875 & $77.8 \%$ & $5.07 \%$ & $73.8 \%$ \\
\hline Full financing & Flexible wage & $23.1 \%$ & 0.498 & 0.874 & 0.867 & $70.2 \%$ & $5.15 \%$ & $66.6 \%$ \\
\hline \multicolumn{9}{|l|}{$\mathrm{IWB}=0.4$} \\
\hline \multirow[t]{2}{*}{ No financing } & Fixed wage & & 0.382 & 1.065 & 0.880 & $83.4 \%$ & $4.97 \%$ & $79.3 \%$ \\
\hline & Flexible wage & & 0.468 & 1.068 & 0.870 & $83.6 \%$ & $4.41 \%$ & $79.9 \%$ \\
\hline Full financing & Flexible wage & $47.3 \%$ & 0.727 & 0.874 & 0.845 & $70.1 \%$ & $4.15 \%$ & $67.2 \%$ \\
\hline
\end{tabular}

The case with full financing and fixed wage is equivalent to $I W B=0$. 
Figure 1: Maximum Tax Rate

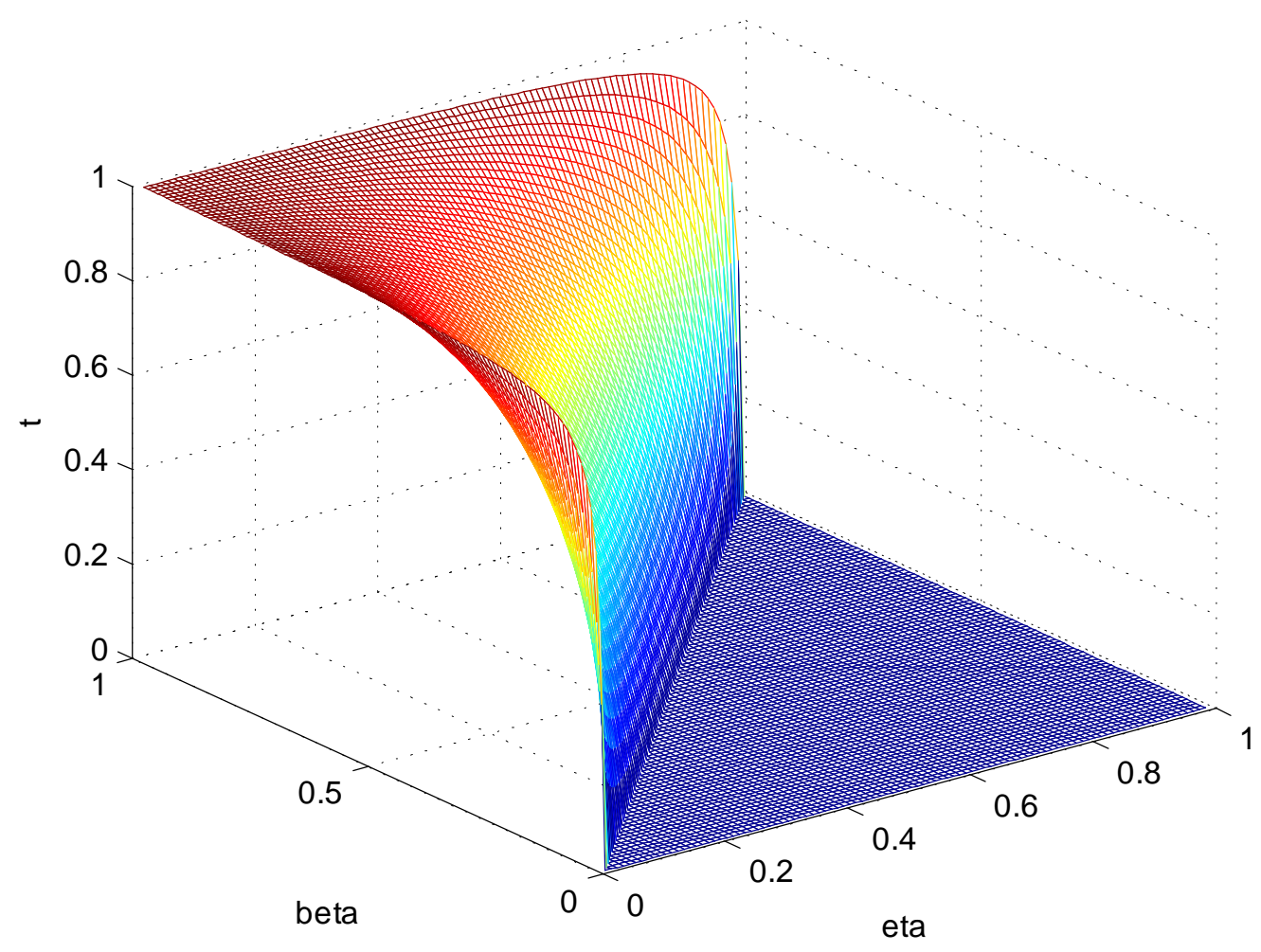


Figure 2: Main Indicators Without Financing
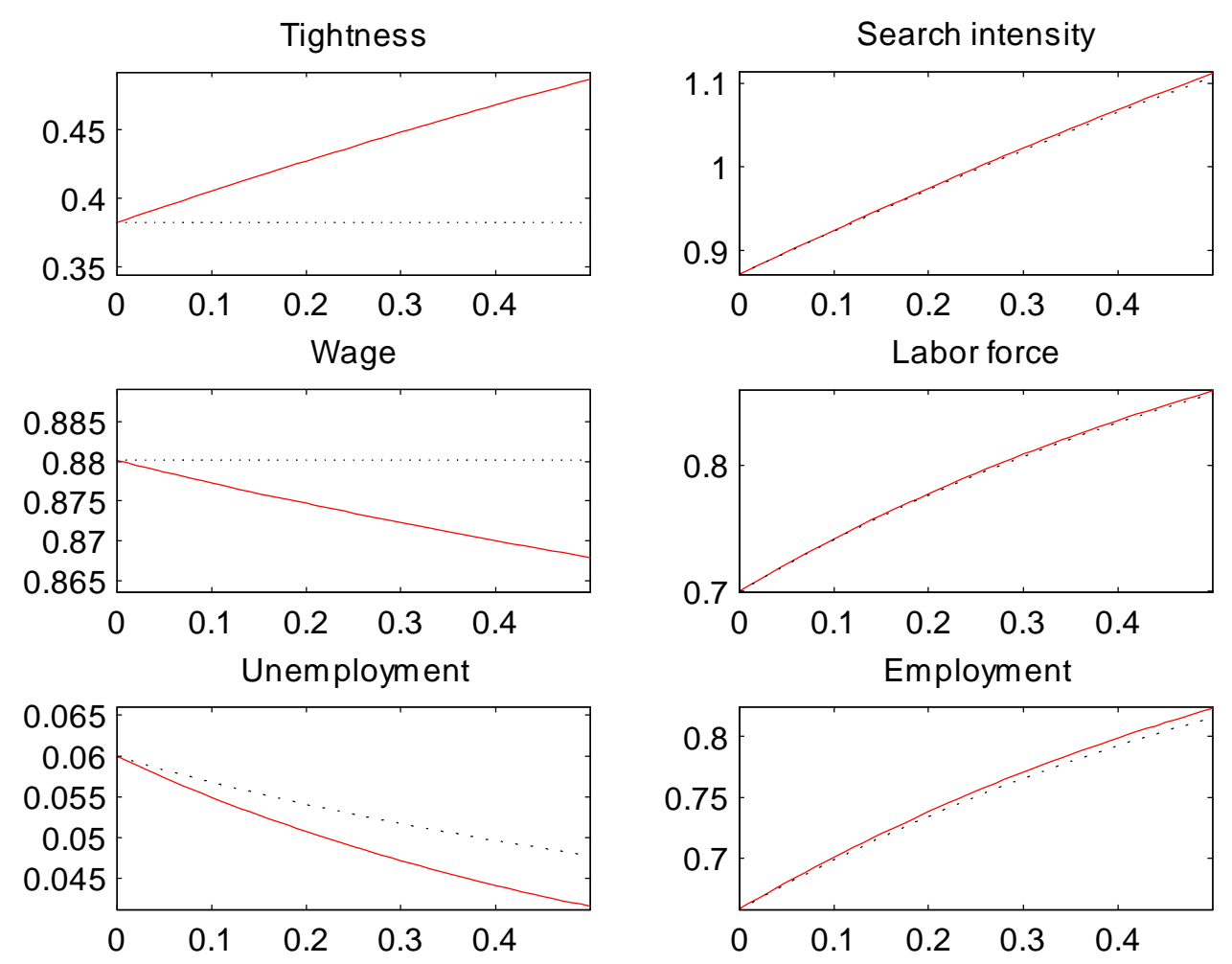
Figure 3: Main Indicators With Financing
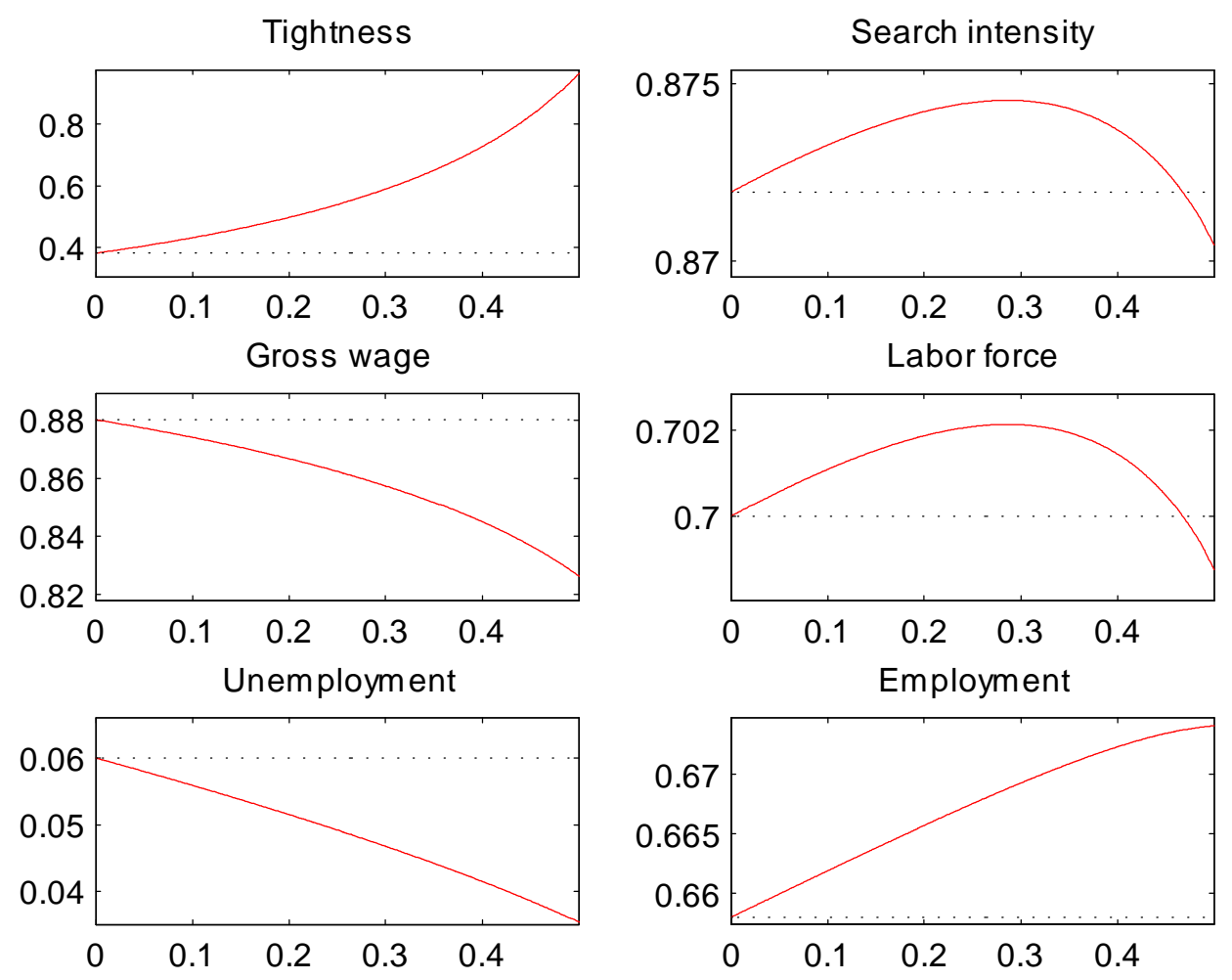